Published in final edited form as:

Chem Commun (Camb). 2016 August 2; 52(64): 9953-9956. doi:10.1039/c6cc04129a.

\title{
Fluorescent vinblastine probes for live cell imaging
}

\author{
Labros G. Meimetis ${ }^{a}, \dagger$, Randy J. Giedt ${ }^{a}, \dagger$, Hannes Mikula ${ }^{a}$, Jonathan C. Carlson ${ }^{a}$, Rainer H. \\ Kohler ${ }^{\mathrm{a}}$, David B. Pirovicha ${ }^{\mathrm{a}}$, and Ralph Weissleder ${ }^{\mathrm{a}, \mathrm{b}}$ \\ Ralph Weissleder: rweissleder@mgh.harvard.edu \\ aCenter for Systems Biology, Massachusetts General Hospital, 185 Cambridge Street, CPZN \\ 5206, Boston, Massachusetts 02114, United States \\ bDepartment of Systems Biology, Harvard Medical School, 200 Longwood Avenue, Boston, \\ Massachusetts 02115, United States
}

\begin{abstract}
Herein we describe the synthesis of several fluorescent analogues of the clinically approved microtubule destabilizing agent vinblastine. The evaluated probes are the most potent described and provides the first example of uptake, distribution and live cell imaging using this well known antimitotic agent.
\end{abstract}

Cytotoxic small molecule chemotherapeutics play an important role in cancer therapy. Microtubule targeting agents in particular, have been part of the medical armamentarium for many decades. ${ }^{1}$ The vinca alkaloid class of natural products isolated from the Madagascar Periwinkle plant (Catharanthus Roseus) and their synthetic derivatives constitute the oldest and largest family of clinically approved anti-mitotic chemotherapeutic drugs. ${ }^{2}$ They have found clinical application for lymphoma, ${ }^{3}$ non-small cell lung cancer, ${ }^{4}$ bladder cancer, ${ }^{5}$ breast cancer, ${ }^{6}$ myeloma,${ }^{7}$ and melanoma. ${ }^{8}$ Despite their widespread clinical use, we still have an incomplete understanding of the pharmacokinetics and intracellular distribution of these compounds. We thus set out to develop cell permeable fluorescent versions of vinblastine to advance our understanding of this drug class in live cells.

Vinblastine binds at the tips of microtubules ${ }^{9}$ inhibiting polymerization and arresting cells in the $\mathrm{G}_{2} / \mathrm{M}$ phase of mitosis. At higher concentrations vinblastine causes microtubule depolymerization and the formation of tubulin-vinblastine aggregates. ${ }^{10}$

More specifically, vinblastine binds at the interface between two $\alpha / \beta$ tubulin heterodimers with $80 \%$ of its surface area buried in the complex (Figure 1). ${ }^{11}$ A portion of the vindoline subgroup of vinblastine is solvent exposed and provides a suitable point for modification and fluorophore attachment.

Correspondence to: Labros G. Meimetis; Randy J. Giedt.

$\dagger$ These authors contributed equally to this body of work.

Electronic Supplementary Information (ESI) available: [details of any supplementary information available should be included here]. See DOI: $10.1039 / \mathrm{x} 0 \mathrm{x} \times 00000 \mathrm{x}$ 
Previously described fluorescent vinblastine conjugates employ derivatization at the $\mathrm{C} 4$ or $\mathrm{C} 4$ ' position. ${ }^{12}$ Unfortunately, these first generation probes provided modest half maximal activity and failed to provide drug distribution in live cells. Based on structural analysis we reasoned that modification at the $\mathrm{C} 3$ position would be an alternative. We thus created a small library of compounds that differ in spacers and fluorochromes to identify the candidate with ideal imaging properties in live cells.

We began the synthesis by treating vinblastine with hydrazine in methanol at $60{ }^{\circ} \mathrm{C}$ to furnish desacetyl vinblastine hydrazide (Scheme 1). ${ }^{13}$ The hydrazide was then dissolved in 1 $\mathrm{M} \mathrm{HCl}$ at $0{ }^{\circ} \mathrm{C}$ and stirred with sodium nitrite for 10 minutes, forming the corresponding acyl azide. ${ }^{14}$ This intermediate was immediately reacted with either ethylenediamine or 1,11,-diamino-3,6,9-trioxaundecane to give amines $\mathbf{1 a}$ and $\mathbf{1} \mathbf{b}$ respectively (see experimental). Varying the linker length between the drug and fluorophore has been shown to affect binding affinity and cellular distribution characteristics, ${ }^{15}$ therefore we selected a short (1a) and long (1b) linker to vary the SAR.

Appropriate fluorophores for live cell imaging must be bright, photostable and non-toxic. We selected the green emitting boron-dipyrromethene based fluorophore (BODIPY) and the far-red emitting silicon-rhodamine ( $\mathrm{SiR}$ ) for conjugation. Both fluorophores have proven particularly successful for live cell imaging applications. ${ }^{16}$ Additionally, we incorporated the recently described boron-modified BODIPY variants (BODIPY-EG), which display enhanced water solubility, and a decreased propensity for getting trapped in lipophilic cellular compartments compared to its difluoro counterpart. ${ }^{17}$ To complete the syntheses, amines $\mathbf{1 a}$ and $\mathbf{1 b}$ were dissolved in a mixture of DMF and triethylamine to which was added the corresponding fluorophore-NHS. This yielded short and long linker vinblastine conjugates of BODIPY (2a/2b), BODIPY-EG (3a/3b), and SiR (4a/4b). We evaluated the absorption and emission characteristics of the different probes at $1 \mu \mathrm{M}$ in PBS $(0.1 \%$ DMSO). All three dyes display small stokes shift and tight absorption and emission bands, characteristic of their respective fluorophore class (Scheme 1), which may be limiting in certain applications but have proven to be suitable for in vitro and in vivo imaging. ${ }^{16}$

Next, we measured the half maximal inhibitory concentration of the probes against the ovarian cancer cell line OVCA429 to determine the effect of linker length and dye selection (Figure 2). Live cells were incubated with the corresponding compound at different concentrations for 3 days followed by analysis using a PrestoBlue ${ }^{\circledR}$ cell viability assay (see experimental). Vinblastine $\left(\mathrm{IC}_{50}=9.45 \mathrm{nM}\right)$ proved to be the most potent followed by BODIPY conjugates $\mathbf{2 a} / \mathbf{2} \mathbf{b}\left(\mathrm{IC}_{50}=30.2 / 43.0 \mathrm{nM}\right)$. The SiR series $\mathbf{4 a} / \mathbf{4} \mathbf{b}$ followed with $\mathrm{IC}_{50}$ $=140.7 / 180.7 \mathrm{nM}$. Interestingly, the BODIPY and SiR series display enhanced potency for the ethylenediamine derivatives over their $\mathrm{PEG}_{3}$ spacer counterparts. Finally, conjugates 3a/3b were the least effective $\left(\mathrm{IC}_{50}=493.7 / 412.2 \mathrm{nM}\right)$ and showed a reversal in inhibition with the long linker derivative $\mathbf{3 b}$ being more potent than the short linker derivative $\mathbf{3 a}$. Commercially available $\mathrm{C} 4$ modified vinblastine-BODIPY (Figure S9, experimental section) had modest activity $\left(\mathrm{IC}_{50}=247.5 \mathrm{nM}\right)$.

Additionally, we evaluated the inhibitory effect the probes have on tubulin polymerization using a tubulin polymerization assay. It is based on the unique feature of DAPI $\left(4^{\prime}, 6-\right.$ 
diamidino-2-phenylindole) fluorescence increasing upon binding to polymerized tubulin. ${ }^{18}$ We measured the time to achieve half maximal tubulin density at $2 \mu \mathrm{M}$ of compound $\left(\mathrm{K}_{\mathrm{d}}\right)$. Vinblastine was the most effective at inhibiting tubulin polymerization $\left(\mathrm{K}_{\mathrm{d}}=5056 \mathrm{~s}\right)$, followed by linker free BODIPY conjugate $\mathbf{2 a}\left(\mathrm{K}_{\mathrm{d}}=3869 \mathrm{~s}\right)$ and $\mathrm{SiR}-\mathrm{PEG}_{3}$ conjugate $\mathbf{4 b}$ $\left(\mathrm{K}_{\mathrm{d}}=3001 \mathrm{~s}\right)$. Commercially available vinblastine-BODIPY had a modest effect with $\mathrm{K}_{\mathrm{d}}=$ $2330 \mathrm{~s}$, as did conjugates $\mathbf{3 b}$, 3a, and 4a with $\mathrm{K}_{\mathrm{d}}=2297,2184$ and $2089 \mathrm{~s}$ respectively.

Next, we acquired high-resolution images of the most potent conjugate 2a at varying concentrations in the human fibrosarcoma cell line HT1080, transfected to express RFP tubulin (Figure 3).

At high probe concentration we observed the formation of microtubule paracrystals, a unique imaging phenotype specific to vinblastine. ${ }^{19}$ This occurs when microtubules depolymerize into vinca-bound $\alpha / \beta$ tubulin heterodimers followed by reorganization to form birefringent uniaxial crystals. ${ }^{20}$ At lower agonist concentrations of $10 \mu \mathrm{M}$ and $1 \mu \mathrm{M}$ probe 2a causes microtubule depolymerisation into tubulin aggregates in addition to having cytoplasmic distribution. This confirms previous reports of vinblastines propensity to only bind microtubule tips, thus leading to the majority of intracellular drug being in an unbound state. Intrigued by the microtubule paracrystalline formation induced by probe $\mathbf{2 a}$ we desired to observe the effects of the remaining probes on microtubule reorganization.

Probes $\mathbf{2 b}, \mathbf{3 a} / \mathbf{3 b}$ and $\mathbf{4 a / 4 b}$ were incubated in OVCA429 cells transfected with CellLight ${ }^{\circledR}$ tubulin-RFP, washed once with media then imaged (Figure 4). Average paracrystal length was determined using MATLAB software (see experimental). We observed the $\mathrm{PEG}_{3}$ versions $\mathbf{2 b}, \mathbf{3 b}$, and $\mathbf{4 b}$ provided a greater density and paracrystal length compared to their short linker counterpart's.

The $\mathrm{PEG}_{3}$ analogue $\mathbf{2 b}$ gave similar paracrystal size compared to native vinblastine ( 8.44 $\mu \mathrm{m})$. The boron-modified BODIPY derivatives $\mathbf{3 a}$ and $\mathbf{3 b}$ also produced paracrystals. Unfortunately, both displayed an increased propensity for loss of signal (agonist) after

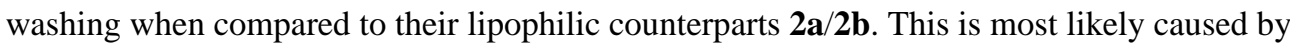
the enhanced water solubility of the ethylene glycol modified BODIPY's and their decreased binding affinity. Interestingly, no paracrystal formation was observed in the siliconrhodamine derivative 4a. However, the cellular phenotype was observed in the $\mathrm{PEG}_{3}$ analogue $\mathbf{4 b}$ with dimensions comparable to the short linker counterpart's $\mathbf{2 a} / \mathbf{3 a}$. We hypothesize that the zwitterionic nature of the silicon rhodamine probe impedes paracystal formation by providing non-favorable interactions between adjacent tubulin heterodimers.

In conclusion, we have designed and synthesized a small series of cell permeable vinblastine-fluorophore conjugates, several of which retain the potency of the therapeutic compound and provide the only live cell imaging and cellular distribution of this mitotic inhibitor. We envision these probes to find use in the study of single cell pharmacokinetics, pharmacodynamics and drug transport mechanisms. Finally, the vinblastine-SiR probe $\mathbf{4 b}$ may find use in stimulated emission depletion (STED) microscopy to provide structural insight of microtubule reorganization by vinblastine. 


\section{Supplementary Material}

Refer to Web version on PubMed Central for supplementary material.

\section{Acknowledgments}

This work was supported in part by the National Institutes of Health (NIH) grant 5RO1EB010011-06 and the Department of Defense Breast Cancer Research Program BC134081.

\section{Notes and references}

1. Dumontet C, Jordan MA. Nat Rev Drug Discovery. 2010; 9:790-803. [PubMed: 20885410]

2. Noble RL, Beer CT, Cutts JH. Ann NY Acad Sci. 1958; 76:882-894. [PubMed: 13627916]

3. Lucas DM, Still PC, Pérez LB, Grever MR, Kinghorn AD. Curr Drug Targets. 2010; 11:812-822. [PubMed: 20370646]

4. Ferrara R, Pilotto S, Peretti U, Caccese M, Kinspergher S, Carbognin L, Karachaliou N, Rosell R, Tortora G, Bria E. Expert Opin Pharmacother. 2016:1-17. 2016.

5. Bellmunt J, Théodore C, Demkov T, Komyakov B, Sengelov L, Daugaard G, Caty A, Carles J, Jagiello-Gruszfeld A, Karyakin O, Delgado FM, Hurteloup P, Winquist E, Morsil N, Salhi Y, Culine S, Maase HVD. J Clin Oncol. 2009; 27:4454-4461. [PubMed: 19687335]

6. Bonneterre J, Penel N. Expert Opin Pharmacother. 2008; 16:2901-2910. [PubMed: 18937621]

7. Hussein MA. Oncologist. 2003; 8:39-45. [PubMed: 14671227]

8. Bhatia S, Tykodi SS, Thompson JA. Oncology. 2009; 23:488-496. [PubMed: 19544689]

9. Wilson L, Jordan MA, Morse A. J Mol Biol. 1982; 159:125-149. [PubMed: 7131559]

10. Donoso JA, Haskins KM, Himes RH. Cancer Res. 1979; 39:1604-1610. [PubMed: 427800]

11. Gigant B, Wang C, Ravelli RBG, Roussi F, Steinmetz MO, Curmi PA, Sobel A, Knossow M. Nature. 2005; 435:519-522. [PubMed: 15917812]

12. Chatterjee SK, Laffray J, Patel P, Ravindra R, Qin Y, Kuehne ME, Bane SL. Biochemistry. 2002; 41:14010-14018. [PubMed: 12437358] Eikesdal HP, Landuyt W, Dahl O. Cancer Lett. 2002; 178:209-217. [PubMed: 11867206] Rai SS, Wolff J. FEBS Lett. 1997; 416:251-253. [PubMed: 9373163]

13. Barnett CJ, Cullinan GJ, Gerzon K, Hoying RC, Jones WE, Newlon WM, Poore GA, Robison RL, Sweeney MJ, Todd GC. J Med Chem. 1978; 21:88-96. [PubMed: 412968]

14. Conrad RA, Cullinan GJ, Gerzon K, Poore GA. J Med Chem. 1979; 22:391-400. [PubMed: 430477]

15. Kim E, Yang KS, Giedt RJ, Weissleder R. Chem Comm. 2014; 50:4504-4507. [PubMed: 24663433]

16. Kim E, Yang KS, Kohler RH, Dubach JM, Mikula H, Weissleder R. Bioconjug Chem. 2015; 26:1513-1518. [PubMed: 26017814] Turetsky A, Kim E, Kohler RH, Miller MA, Weissleder R. Sci Rep. 2014; 4:1-7.

17. Courtis AM, Santos SA, Guan Y, Hendricks AJ, Ghosh B, Szantai-Kis MD, Reis SA, Shah JV, Mazitschek R. Bioconjug Chem. 2014; 25:1043-1051. [PubMed: 24797834]

18. Bonne D, Heusele C, Simon C, Pantaloni D. J Biol Chem. 1985; 260:2819-2825. [PubMed: 3972806]

19. Nakamura Y, Ishigaki Y. Oncol Lett. 2014; 8:2387-2392. [PubMed: 25364400] Moisoi N, Erent M, Whyte S, Martin S, Bayley PM. J Cell Sci. 2002; 115:2367-2379. [PubMed: 12006621] Gundersen GG, Khawaja S, Bulinski JC. J Cell Biol. 1987; 105:251-264. [PubMed: 2886509]

20. Na GC, Timasheff SN. J Biol Chem. 1982; 257:10387-10391. [PubMed: 7107609] 
a.

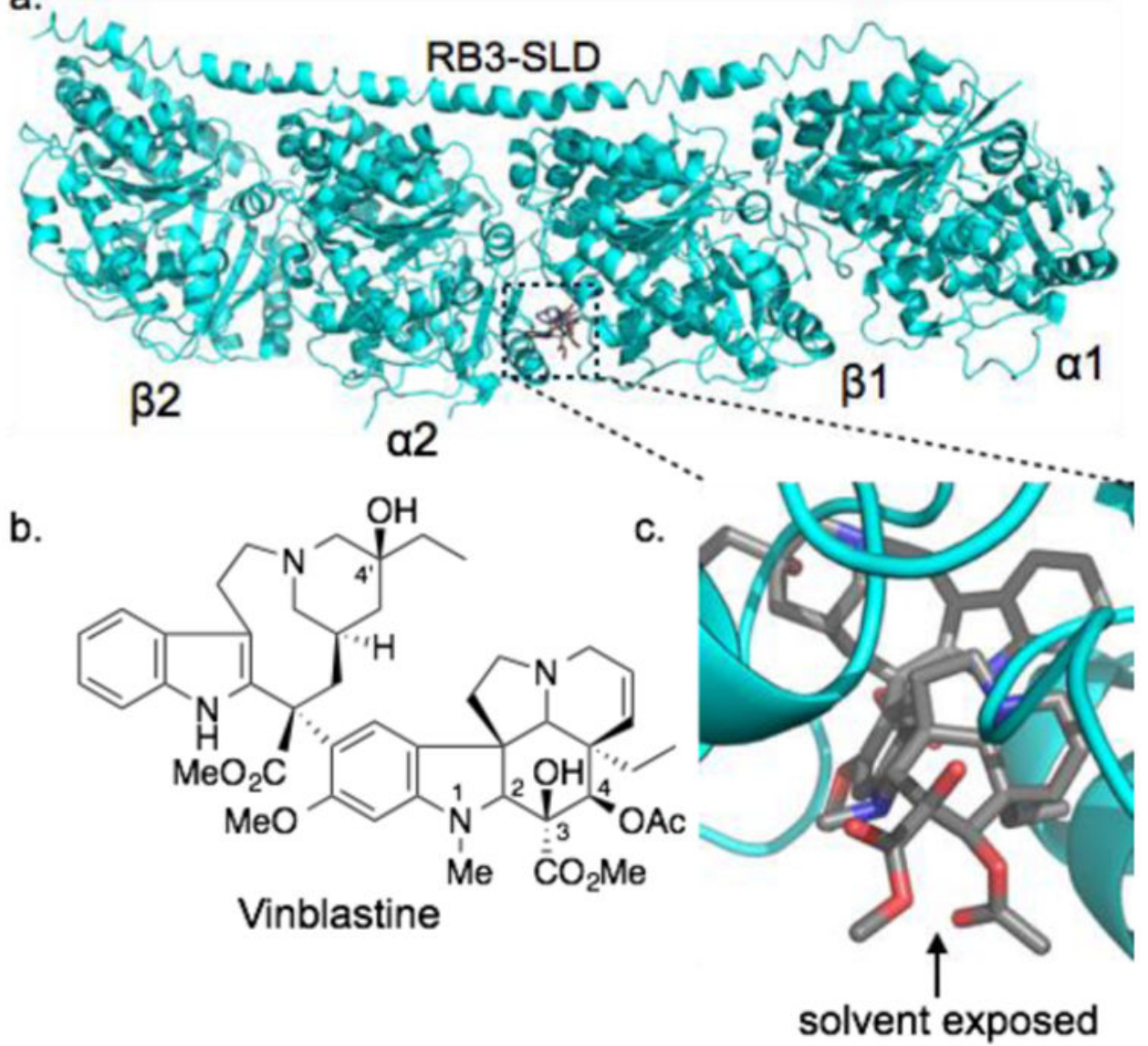

Figure 1.

(a) Vinblastine bound between two $\alpha / \beta$ tubulin heterodimers (Protein Data Bank ID code 1Z2B). (b) Structure of vinblastine. (c) A portion of the vindoline subgroup is solvent exposed, providing a point for fluorophore attachment. 

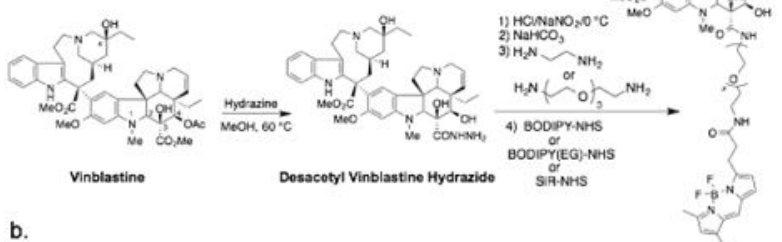

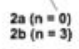
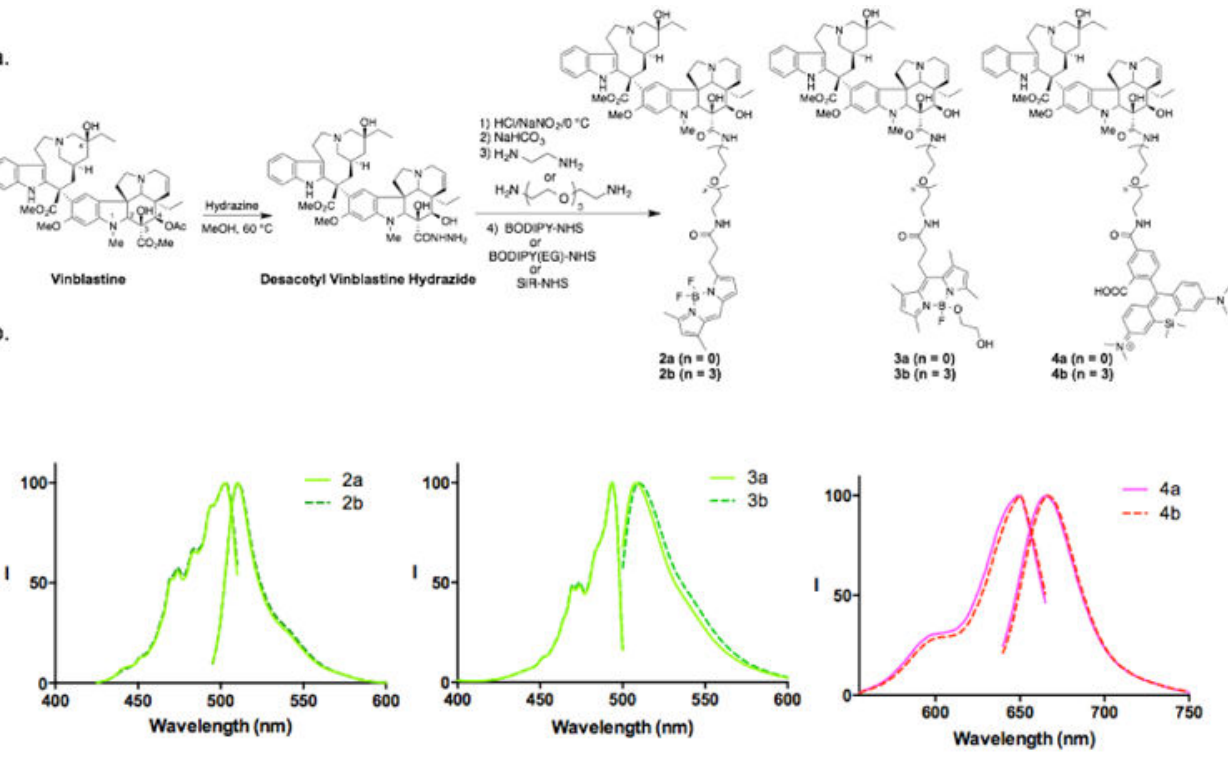

Figure 2.

(a) $\mathrm{IC}_{5} 0$ curves of vinblastine, vinblastine-fluorophores $\mathbf{2 a} / \mathbf{2 b}, \mathbf{3 a} / \mathbf{3 b}, \mathbf{4 a} / \mathbf{4} \mathbf{b}$, and commercially available vinblastine-BODIPY (VBLS) in OVCA429 cells using a fluorometric assay. (b) Plot of tubulin polymerization assay. $\mathrm{K}_{\mathrm{d}}$ represents the time it takes to reach half maximal microtubule density with $2 \mu \mathrm{M}$ of agonist (see experimental). * Nonsignificant compared to vinblastine. 
a.
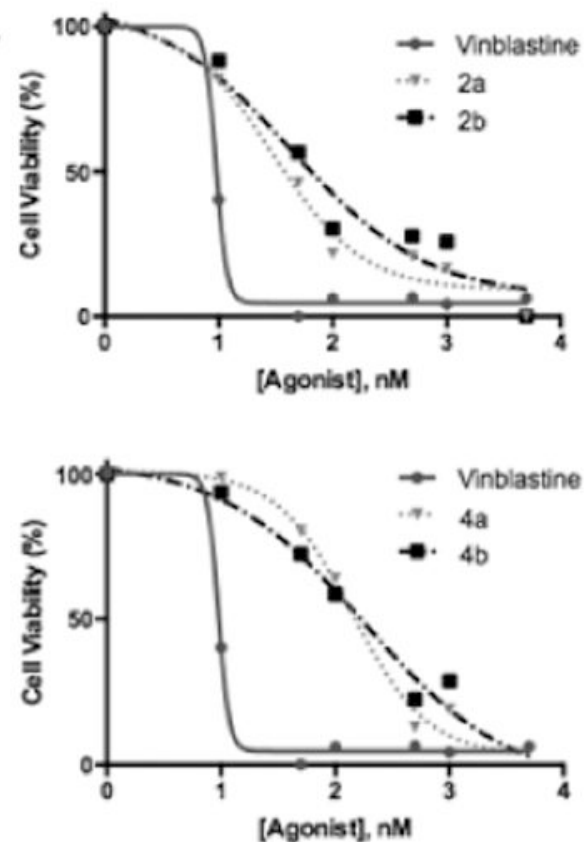

b.

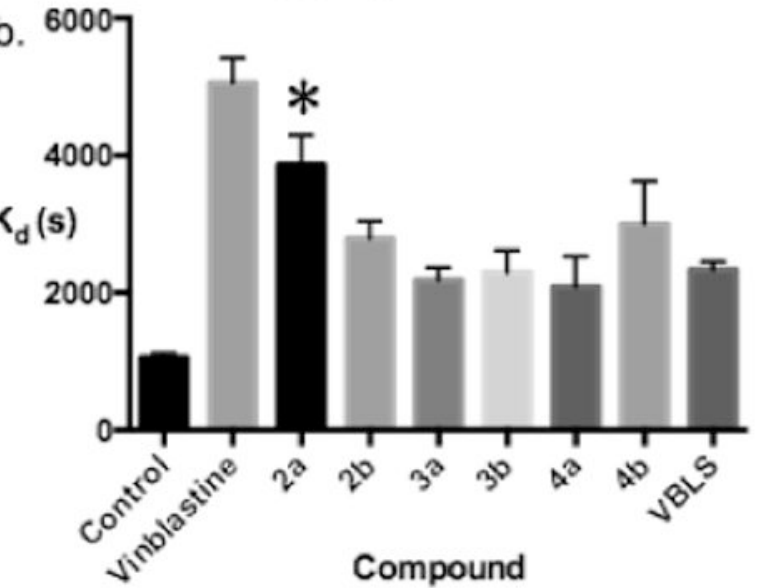

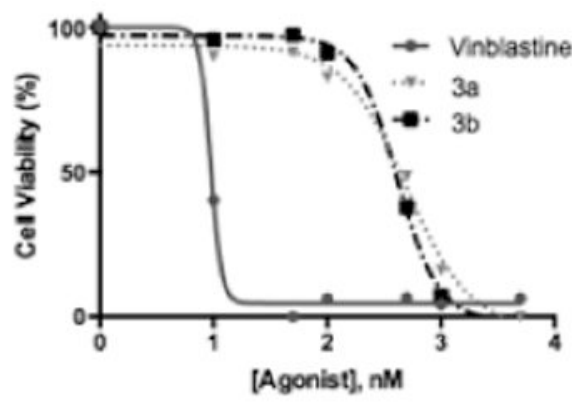

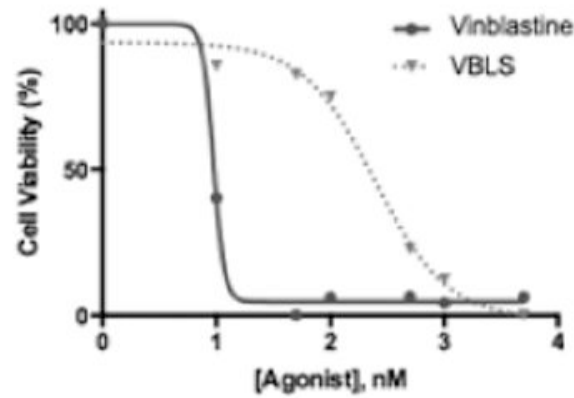

Figure 3.

High-resolution live cell imaging of the most potent vinblastine conjugate 2a in HT1080 cells expressing tubulin RFP. Cells were incubated for $3 \mathrm{~h}$ at (a) $100 \mu \mathrm{M}$ (b) $10 \mu \mathrm{M}$, and (c) $1 \mathrm{~h}$ at $1 \mu \mathrm{M}$. 
a.
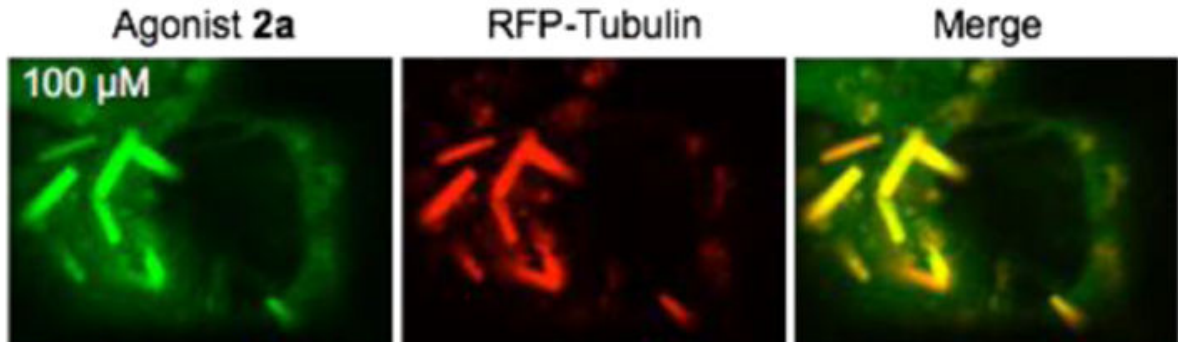

b. $10 \mu \mathrm{M}$
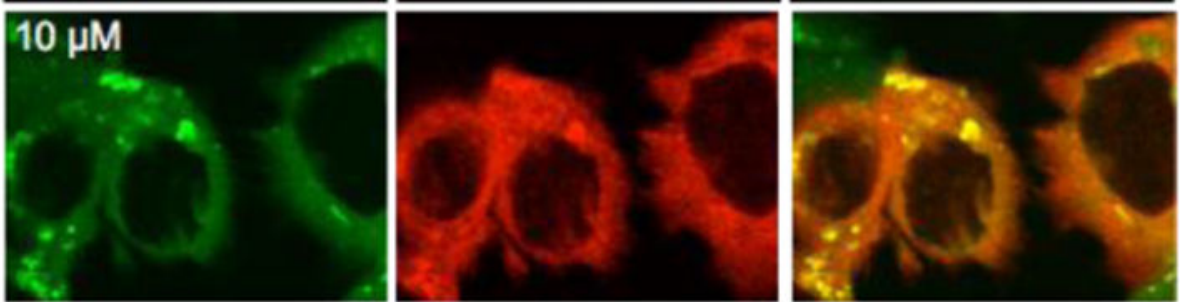

c. $1 \mu \mathrm{M}$
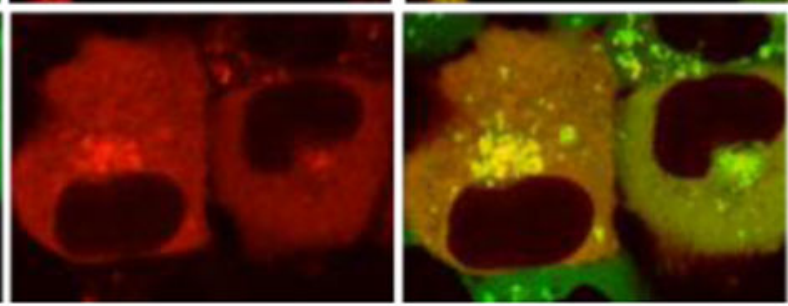

Figure 4.

Live cell imaging of vinblastine-fluorophore conjugates in OVCA429 cells transfected with CellLight ${ }^{\circledR}$ RFP tubulin. The cells were incubated with $100 \mu \mathrm{M}$ of probe for $3.5 \mathrm{~h}$ in media followed by a single wash and then imaged. Average paracrystal length is displayed at the top right. $\mathrm{Bar}=10 \mu \mathrm{m}$. 


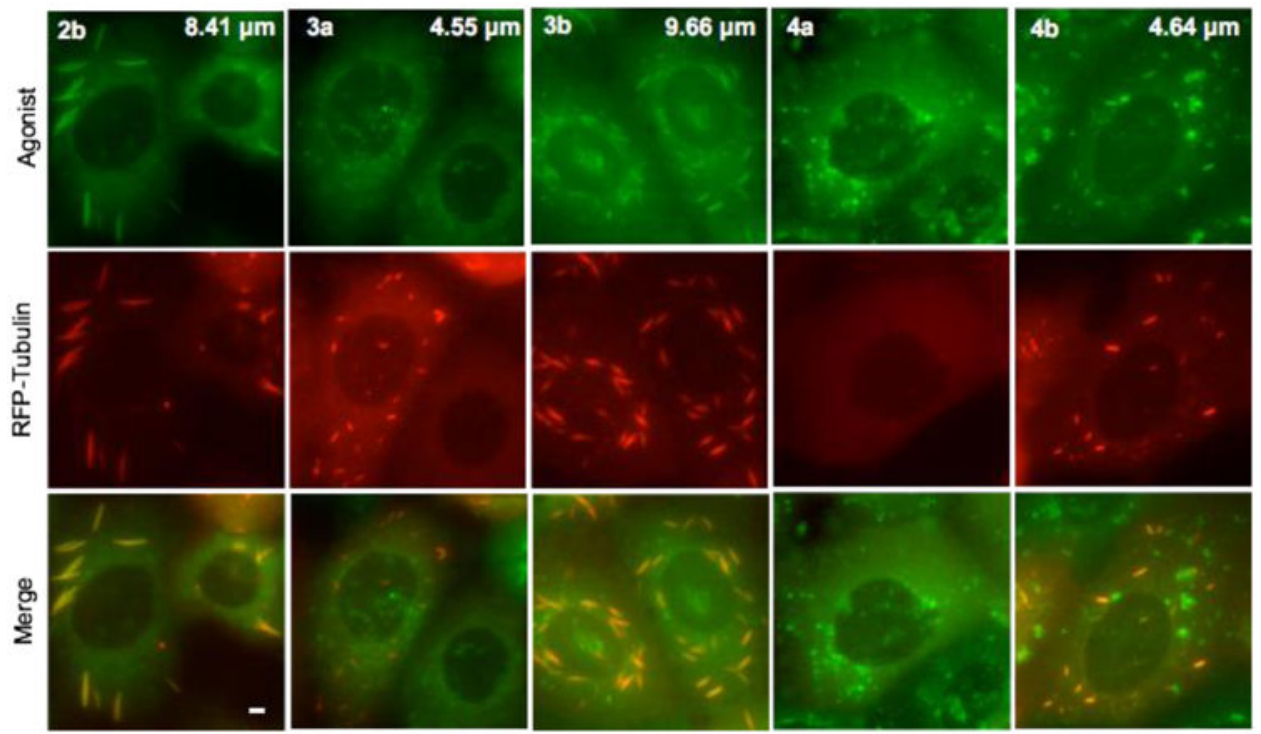

Scheme 1.

(a) Synthesis of vinblastine-fluorophore conjugates. (b) Excitation and emission spectra of vinblastine conjugates in phosphate buffered saline (PBS). 